\title{
CLASSICAL ECONOMICS AND HAPPENSTANCE
}

Imre Szabó

\begin{abstract}
Classical economic theory is built on the assumption that prices, incomes and the utility function can be determined more or less precisely and using the tools of mathematics - the derivative and the Lagrange multiplicator - their correlations can be recognised. Those tools, in practice, mean a total exclusion of uncertainty. They fail to consider that random chance may not only override the preconditions of a problem to be solved but also the whole problem.
\end{abstract}

JEL codes: $\mathrm{D} 84, \mathrm{D} 85$

Keywords: invisible hand, derivative, utility function, profit maximising problem, marginal utility, Lagrange multiplicator, shadow prices

Economic theory built on a deterministic world view had culminated in the general equilibrium theory by the second half of the 2oth century, which has been its most important or at least most spectacular result so far (cf. Medvegyev, 1978). Note, however, that differentiability has been the result of the physical particularly of the mechanical world view. Its mathematical apparatus is, in fact, a set of tools of optimum calculations, which directly derive from classical mechanics. It is no accident that the main tool of micro-economics, the Lagrange multiplicator method, is named after one of the main designers of classical mechanics. The general equilibrium theory is, in effect, an equilibrium born from the mechanical world view.

A major problem with classical economics is that random chances and risks are not considered or are not managed according to their weight. In contrast, the risks appearing on the financial markets are analysed in-depth using the tools of probability and a wide range of methods have been developed for their management (cf. Medvegyev-Száz, 2010). For instance, the classical theory assumes that utility function exists, it is known and is not subject to external impacts. Even if it acknowledges accidental outcomes, it assumes their probability to be known.

$1 \quad$ Imre Szabó, Associate Professor, Budapest Corvinus University. E-mail: szaboim@uni-corvinus. hu. 
What estimation is used for those probabilities is unimportant from this perspective. In other words, it is not the most important question whether the probabilities are statistically sound or subjective. The main implicit assumption is that things can be foreseen at least in the short run. You cannot emphasise enough that uncertainty is nothing but the denial of predictability.

These days everybody has a first-hand experience of what uncertainty means. The emergency situation caused by the corona virus is an excellent albeit unfortunate example. All over the world living conditions and people's goals changed from one day to the next. You cannot even make a forecast for a few hours' time due to the virus situation. It has also become quite clear what uncertainty and random chances mean. Obviously, the 'virus experiment' and its impact on the economy cannot be freely repeated. You have no idea about the probability of the economic damage caused by the virus.

So, much criticism can be said of classical economics. On the other hand, it is a treasure trove of major thinkers' work accomplished in the course of several centuries. In what follows, we shall try to take a glimpse into the magnificent 'building' of the classical theory, which - although it can be strongly criticised and can only be applied in a relatively narrow scope - has exercised a major impact on economic thinking.

\section{THE INVISIBLE HAND}

In the course of economic research, classical economists such as Adam Smith recognised that if people are allowed to work for their own interest without paying attention to the interests of society, the common goals will be promoted most effectively led by the market. The discovery of the relationship may be called a true popular theorem, as it had been expressed before Adam Smith and may have been part of common knowledge in his time. Anyway, he presented the following mysterious and slightly paradoxical statement in his work The Wealth of Nations published in 1776 (smith, 1776, Book IV, Chapter II, para IX):

"Every individual endeavours as much as he can ... to employ his capital ... so that its produce may be of the greatest value. ... He generally... neither intends to promote the public interest nor knows how much he is promoting it. He intends only his own security ... his own gain and he is in this...led by an invisible hand to promote an end which was no part of his intention... By pursuing his own interest he frequently promotes that of society more effectually than when he really intends to promote it."

A problem appearing at this point is that random chance and uncertainty have not been taken into account. Keynes's main contribution is emphasising that the invisible hand is faced with more hardship under uncertain conditions. Note, 
however, what a huge step was made forward by presenting the theory of the invisible hand. Modern thinking is built on the criticism of the invisible hand, but let us not forget that the theory was a revolutionary idea with a serious critical edge.

The next question is about the way markets exercise their regulatory effect. The answer is obvious: by way of the evolution of the prices of goods. If the price of goods is 'too high', production will increase leading to the reduction of prices, while if they are 'too low', production will be reduced and prices will go up. So the question is what it means that the price of goods is too high or too low, in other words, how prices evolve.

This kind of flexibility is pure illusion today particularly for internationally coordinated production chains. On the other hand, it can be clearly observed on the financial markets where, in effect, expectations linked to the ups and downs of pure chance are bought and sold (cf. Száz, 2019).

The first answer to the question of the evolution of prices was the labour theory of value. It says the price of goods fluctuates around their value represented by the labour required to produce them. The idea was definitely sound, on the other hand, detailed descriptions of how it was implemented carried a number of contradictions damaging its applicability. So, in time, other approaches were offered to explain the evolution of prices. According to the theory of marginal utility, the prices of goods equal their marginal utilities.

\section{MATHEMATICAL ANALYSIS}

We must make a detour before going on and not in the direction of mathematics but that of physics. Mankind has been intrigued by the starry skies for thousands of years. Why is the place of stars fixed while some celestial bodies 'meander' on a strange cycloid track? Modern answers commenced with the measurements made by Galilei who found that the distance travelled by a free falling object is directly proportional to the square of time. The key to understanding motion was the concept of velocity introduced by Newton. The introduction of the concept had been made possible by the mathematical definition of the difference quotient. According to it, the velocity of a body is the derivative of the path function. Then the concept of velocity could be used to explain that the event of the Moon orbiting round the Earth is the same as an apple falling off a tree. All that has basically changed mankind's vision of the world - not only of the physical but also of the social world as well. It has become the foundation of the Enlightenment since if the same laws apply to bodies on Earth and heavenly bodies, the same laws should apply to both serfs and kings. 
Adam Smith's concept of society fits into the same line. The theory of the invisible hand, in fact, says that the world does not operate out of some ruler's wisdom or benevolence.

You cannot overemphasise that the foundation for all that had been the concept of the derivative introduced by Newton and Leibnitz independently of each other, which grew into mathematical analysis, one of the most important chapters of mathematics. Mathematical analysis developed in the course of centuries thanks to the works of the greatest mathematicians, such as Euler, Cauchy, Lagrange, Bolzano, Weierstrass, Riemann and Lebesgue beginning from the second half of the 17 th to the beginning of the 2oth century.

That marked chapter of mathematics did not only lay the foundations for modern physics but also for almost all sciences including economics.

\section{THE THEORY OF MARGINAL UTILITY}

While velocity is the derivative of the path function, in an analogy, marginal utility is the derivative of the utility function. The real question, however, is why this concept is interesting, why the price of a product is equal to its marginal utility. The answer is of major importance for economics but from a mathematical perspective it requires the knowledge of an underlying area of analysis, termed conditional extreme values. In the following we shall need some formalism as well. Let us assume that $n$ kinds of products are produced and consumed in an economy. Then a product series is:

$\mathbf{x}=\left(x_{1}, \ldots, x_{n}\right) \in \mathbb{R}^{n}$.

Let us assume for a start that consumers have the ability to choose 'rationally', which is expressed by saying consumers have $\mathcal{R} \subset \mathbb{R}^{n} \times \mathbb{R}^{n}$ transitive and complete relation, i.e. preference sorting. To be able to examine such an extreme value problem, the preference relation is usually substituted with a 'preference indicator function', also called a 'utility function', i.e. with a $u: \mathbb{R}^{n} \rightarrow \mathbb{R}$ function representing $\mathcal{R}$ preference relation, whereby we mean that a product series $\mathbf{x} \in \mathbb{R}^{n}$ takes precedence over a product series $\mathbf{y} \in \mathbb{R}^{n}$ if its utility function is not lower in the following vector:

$\mathbf{x} \mathcal{R} \mathbf{y} \Leftrightarrow \mathrm{u}(\mathbf{x}) \geq u(\mathbf{y})$ 
Consumers define the $\mathbf{x}=\left(x_{1}, \ldots, x_{n}\right) \in \mathbb{R}^{n}$ vector of their consumer goods, that given

$\mathbf{p}=\left(p_{1}, \ldots, p_{l}\right) \in \mathbb{R}_{+}^{l}$ prices and $w \in \mathbb{R}_{+}$income,

they maximise the utility of $\mathrm{u}(\mathbf{x})$ under budgetary condition $\langle\mathbf{p}, \mathbf{x}\rangle \leq w$. Accordingly, consumers' behaviour can be described with the following conditional extreme value problem series parametred with price vector $\mathbf{p} \in \mathbb{R}_{+}^{l}$ and income $w \in \mathbb{R}_{+}$

$\left\{\begin{array}{l}\mathrm{u}(\mathbf{x}) \rightarrow \max \\ \langle\mathbf{p}, \mathbf{x}\rangle \leq w\end{array}\right.$

The Lagrange function of the problem is function $\mathcal{L}: \mathbb{R}^{l} \times \mathbb{R} \rightarrow \mathbb{R}$, where - in the event $\forall \mathbf{x} \in \mathbb{R}^{l}, \lambda \in \mathbb{R}$

$\mathcal{L}(\mathbf{x}, \lambda) \doteq \mathrm{u}(\mathbf{x})-\lambda(\langle\mathbf{p}, \mathbf{x}\rangle-w)$

Subject to assuming equality or inequality in the condition, the Lagrange or the Kuhn-Tucker multiplicator theorems can be applied. Therefore, if the solution of the problem is a $\mathbf{x}_{0} \in \mathbb{R}^{l}$ vector, then $\exists \lambda \in \mathbb{R}$ Lagrange multiplicator, and in case of $\forall i=1, \ldots, l$

$\partial_{i} \mathrm{u}\left(\mathbf{x}_{0}\right)=\lambda \cdot p_{i}$

Assuming that not more than two products are examined, the following formula is given:

$-\frac{\partial_{1} u\left(x_{1}^{0}, x_{2}^{0}\right)}{\partial_{2} u\left(x_{1}^{0}, x_{2}^{0}\right)}=-\frac{p_{1}}{p_{2}}$.

- Adopting a mathematical perspective, relationship (2) means - as it is usually fulfilled according to the Lagrange multiplicator theorem - that the budget line touches the level set $u^{-1}\left(u\left(x_{1}^{0}, x_{2}^{0}\right)\right) \subset \mathbb{R}_{+}^{2}$ of the utility function $u$ belonging to the optimal point $\left(x_{1}^{0}, x_{2}^{0}\right) \in \mathbb{R}_{++}^{2}$, i.e. its indifference curve. Thus, the definition of the optimal point can be visualised by pushing the indifference curves of the utility function until they touch the budget line.

- From the perspective of economics, relationship (2) can be interpreted by saying that the ratio of the marginal utility of the two products equals the ratio of their prices at the optimal point $\left(x_{1}^{0}, x_{2}^{0}\right)$. In addition, since the marginal 
rate of substitution equals the opposite of the quotient of marginal utilities, this relationship leads to a fundamental law of microeconomics, i.e. at the optimal point $\left(x_{1}^{0}, x_{2}^{0}\right)$ the marginal rate of substitution equals the opposite of the price ratio:

$$
\frac{d x_{2}}{d x_{1}}=-\frac{p_{1}}{p_{2}} .
$$

- Finally, let us assume that the second product is money. Then relationship (2) is simplified to the following equation:

$\partial_{i} \mathrm{u}\left(\mathbf{x}_{0}\right)=\mathbf{p}_{i}$,

which is actually another way of stating the well-known fact that the marginal utility of a product equals its price. This is quite interesting, because even people engaged in economics often fail to realise that the introduction of such a basic concept, on the one hand, requires sound mathematical skills and, on the other hand, how simple it is if you are in possession of them.

\section{THE LAGRANGE MULTIPLICATOR}

By identifying the Lagrange function of the profit maximisation problem, the conditions have in fact been priced. To examine that pricing, let us introduce the consumer's indirect utility function, identified as the value function of problem series (1), namely, it means function $u^{v}: \mathbb{R}_{+}^{l} \rightarrow \mathbb{R}$, where for price vector $\mathbf{p} \in \mathbb{R}_{+}^{l}$ and income $w \in \mathbb{R}_{+}$:

$u^{\vee}(\mathbf{p}, w) \doteq \sup _{\langle\mathbf{p}, \mathbf{x}\rangle \leq w} \mathrm{u}(\mathbf{x})$

According to the envelope theorem named Roy's identity in this special case, it is true that the partial derivative of the indirect utility function by income, which can be regarded as a kind of marginal utility, equals the Lagrange multiplicator:

$\partial_{2} u^{\vee}(\mathbf{p}, w)=\lambda$

In line with that relationship the Lagrange multiplicator equals marginal utility in some sense, so it can be deemed a price - that is why it is called a shadow price.

The linear case is an even better explanation. Let us take the special case of a conditional extreme value problem limited by inequalities when both the tar- 
get function and the conditional functions are linear, i.e. a linear programming problem:

$\left\{\begin{array}{c}\langle\mathbf{c}, \mathbf{x}\rangle \rightarrow \max \\ \left\langle\mathbf{a}_{\mathbf{1}}, \mathbf{x}\right\rangle \leq b_{1}, \ldots,\left\langle\mathbf{a}_{\mathbf{m}}, \mathbf{x}\right\rangle \leq b_{m}\end{array}\right.$,

Or in its usual form

$\left\{\begin{array}{c}\langle\mathbf{c}, \mathbf{x}\rangle \rightarrow \max \\ \mathbf{A x} \leq \mathbf{b}\end{array}\right.$,

where

$\mathbf{A} \doteq\left[\begin{array}{c}\mathbf{a}_{\mathbf{1}}^{\mathbf{T}} \\ \vdots \\ \mathbf{a}_{\boldsymbol{m}}^{\mathbf{T}}\end{array}\right] \in \mathbb{R}^{m \times n} \quad$ és $\quad \mathbf{b} \doteq\left[\begin{array}{c}b_{1} \\ \vdots \\ b_{m}\end{array}\right] \in \mathbb{R}^{m}$

The Lagrange function of problem (3) is the function $\mathcal{L}: \mathbb{R}^{m} \times \mathbb{R}^{n} \rightarrow \mathbb{R}$, where for $\forall \mathbf{x}=\left(x_{1}, \ldots, x_{n}\right) \in \mathbb{R}^{n}$ and $\forall \mathbf{y}=\left(y_{1}, \ldots, y_{n}\right) \in \mathbb{R}^{m}$

$\mathcal{L}(\mathbf{x}, \mathbf{y})=\mathcal{L}\left(\mathbf{x},\left(y_{1}, \ldots, y_{n}\right)\right) \doteq\langle\mathbf{c}, \mathbf{x}\rangle-\sum_{i=1}^{m} y_{i} \cdot\left(\left\langle\mathbf{a}_{\mathbf{i}}, \mathbf{x}\right\rangle-b_{i}\right)=\langle\mathbf{c}, \mathbf{x}\rangle-\langle\mathbf{y}, \mathbf{A} \mathbf{x}\rangle+\langle\mathbf{y}, \mathbf{b}\rangle$

Let us now take a version of problem (3) where we are looking for a minimum rather than a maximum with variable

$\left\{\begin{array}{c}\langle\mathbf{y}, \mathbf{b}\rangle \rightarrow \min \\ \mathbf{y A} \geq \mathbf{c}\end{array}\right.$

It is also known that the above problems have a complete duality relationship with each other, which means the following:

If one of a pair of dual problems has an optimal solution, the other problem also has an optimal solution, and the value of the two problems is identical.

If the maximum problem is regarded as a problem of profit maximisation, the solutions of its dual problem mean the prices of the production factors used. Since the variables of the dual problem are the Lagrange multiplicators of the original problem, the Lagrange multiplicators can be regarded to be the shadow prices of the production factors. 


\section{SUMMARY}

According to the marginal utility theory, prices can be learnt and calculated which is in practice not true at all, because the use of derivatives means the total exclusion of uncertainty. When we take a utility maximisation problem, we assume that income, price and even the utility function are well known, so - using the Lagrange multiplicator theory - demand can be calculated to an arbitrary decimal precision. The assumption, however, is not true. On the contrary, the main problem regarding the balance of demand and supply is that the conditions under which we maximise are not known at any given moment. What we optimise may vary arbitrarily. The preferences of average market players can change very fast. An optimistic market expectation can turn into a panicky flight on the impact of one news item. In one minute you maximise profit and in the next you minimise loss. In addition, the controlling power of prices can dissolve. If there is great uncertainty, high prices may not reduce demand. The recent story of toilet paper is a trivial example for that. Shops increased their prices significantly, but the shelves remained empty. Later on, when things calmed down, you could get toilet paper again. In such cases prices do not regulate demand, instead, fears and expectations move prices.

Most economic processes evolve subject to a stream of incoming news, which can basically shake all the parameters market players have assumed.

It is well known that in 1720 Newton fell victim to one of the largest share bubbles in world history. His sarcastic remark on the event has been preserved, 'I can calculate the motion of heavenly bodies but not the madness of people'.

\section{REFERENCES}

Ioffe, A. D. - Tiкhomirov, V. M. - Makowski, K. (1979): Theory of Extremal Problems. Amsterdam, New York: North-Holland Pub. Co.

Medvegyev, P. (1978): Az általános egyensúlyelmélet Arrow-Debreu modellje [The Arrow-Debreau model of the general equilibrium theory], manuscript.

Medvegyev, P. - SzÁz, J. (2010): A meglepetések jellege a pénzügyi piacokon [The nature of surprise on financial markets]. Budapest: Nemzetközi Bankárképző Központ.

Sмiтн, A. (1776): An Inquiry into the Nature and Causes of the Wealth of Nations. London: Strahan, W. and Cadell, T.

SzÁz, J. (2019): Kvantitatív pénzügyek [Quantitative finances]. Budapest: Nemzetközi Bankárképző Központ 